\title{
HISTOLOGY AND HISTOCHEMISTRY OF THE LONG BONES IN MICROMELIA
}

BY

\author{
A. T. SPENCER \\ From the Department of Pathology, University of Birmingham
}

(RECEIVED FOR PUBLICATION OCTOBER 11, 1962)

There are many recorded cases of micromelia but no report of the histochemistry of the bones in this condition in papers published recently.

The object of this paper is to describe a case of micromelia in a newborn infant, and to record certain histochemical changes in the epiphyses.

\section{Case Report}

Clinical Findings. The infant was the fifth child born to parents of normal build and stature. The first child was a male stillborn; the second was a female dwarf now aged 12 years; the third and fourth children were both male stillborns, and so far as can be ascertained the stillborn males showed no evidence of dwarfism.

On this occasion pregnancy had been normal and the mother, a patient of Prof. H. C. McLaren, went into labour nine days before the expected date of delivery. The child was delivered by a high forceps technique because of foetal distress as shown by irregularity of the foetal heart. The baby breathed immediately at birth, but its condition soon deteriorated and it became cyanosed and died after 25 hours.

Autopsy Findings. The body was that of a cyanosed, full-term male infant; total length $39.8 \mathrm{~cm}$.; weight $2.92 \mathrm{~kg}$. The typical deformities of micromelia were seen (Fig. 1) with pronounced shortening of the arms $(12.0 \mathrm{~cm}$.) and legs $(11.0 \mathrm{~cm}$.). The face showed general flattening of the features and the frontal bones were prominent.

All bones were well formed and unusually rigid. There was no evidence of bowing or fracturing. The bones of the limbs were greatly shortened. The femur for example was only $6.5 \mathrm{~cm}$. long as compared with an average length of $9.5 \mathrm{~cm}$. in a group of normal cases of similar age. The limb bones appeared to be smaller in all dimensions with the epiphyses reduced in proportion (Figs. 2 and 3) though not abnormal in shape. The ribs, on the other hand, showed a slight swelling at the costochondral junction, which was most marked on the inner aspect (Fig. 3).

The bones of the skull were unusually rigid and appeared to be very well formed indeed. Haemorrhage was seen over the surface of the brain and there was a considerable extravasation of blood into the tissues of the falx and tentorium with a tear $1.5 \mathrm{~cm}$. long in the left side of the tentorium.

Both lungs showed the appearances of atelectasis neonatorum, and the tissue from all lobes of each lung sank in water.

The thyroid, adrenals and pituitary, and organs of all other systems, appeared macroscopically normal.

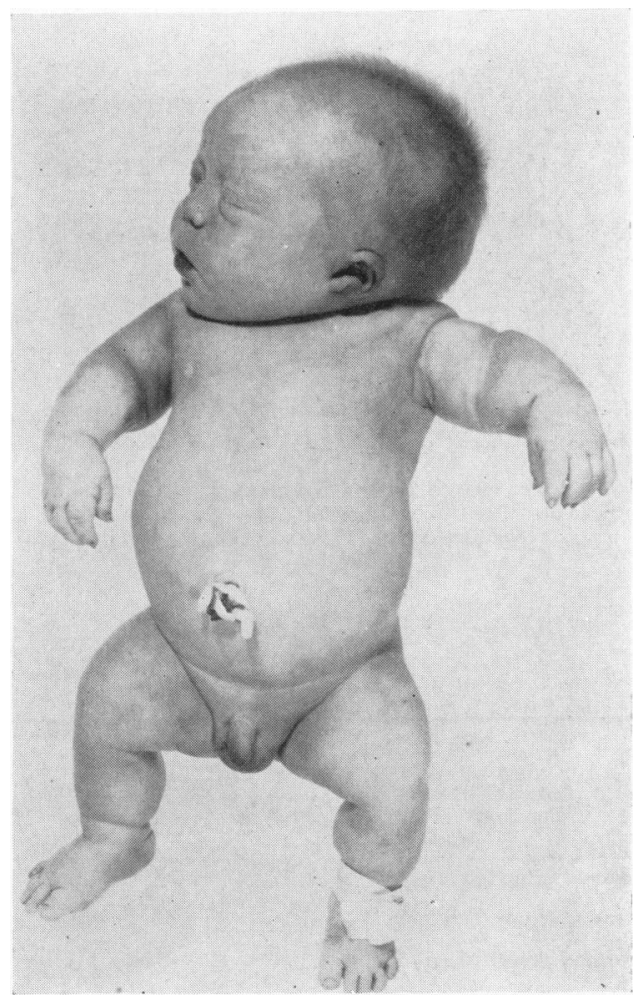

FIG. 1.-The arms and legs are considerably shortened. 


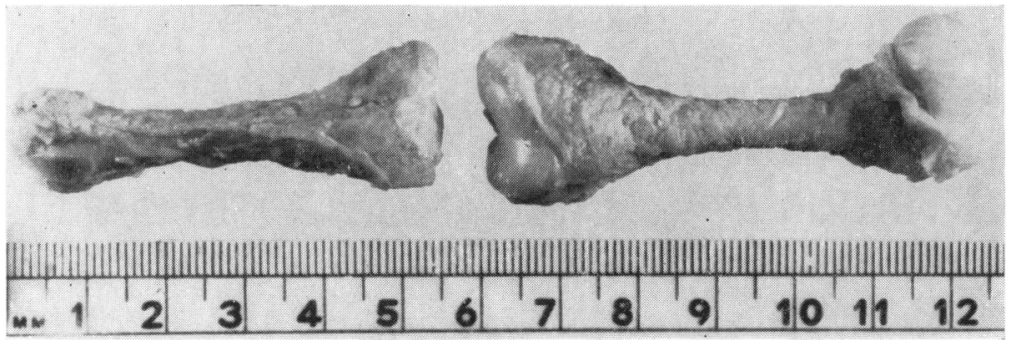

Fig. 2.-The tibia and femur are shortened and the epiphyses are of proportionately smaller size.

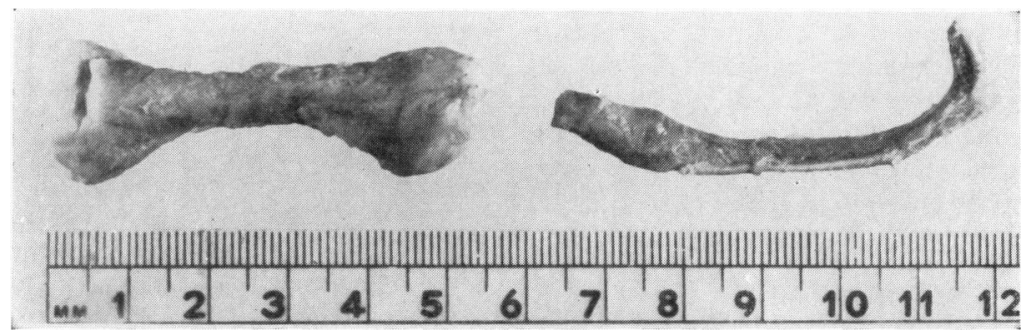

FIG. 3.-The humerus is shortened. A swelling at the costochondral junction is present.

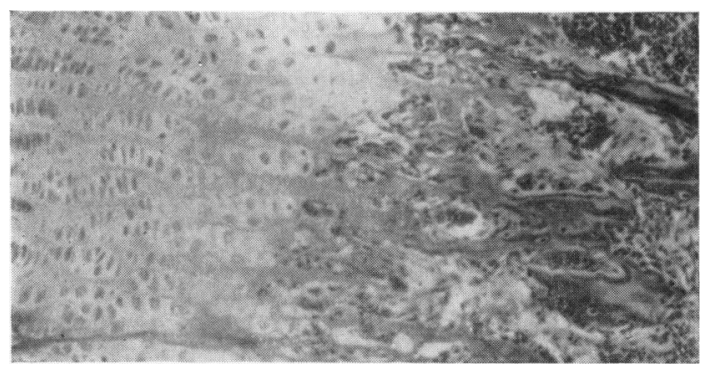

Fig. 4.-Lower end of femur; the cartilage cells are much smaller than normal. The cartilaginous matrix of the epiphysis stains deep pink. (Iron haematoxylin and van Gieson's stain $\times 100$.)

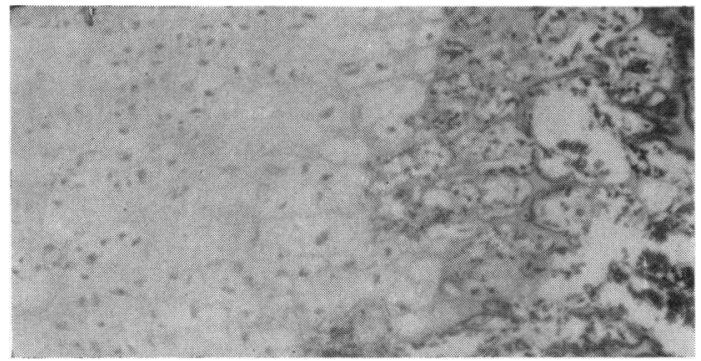

Fig. 5.-Similar field to Fig. 4 from lower end of femur of a control. Iron haematoxylin and van Gieson's stain $\times 100$.)

TABLE

RESULTS OF NITROGEN AND HYDROXYPROLINE ASSAYS

\begin{tabular}{|c|c|c|c|c|c|c|}
\hline \multirow{2}{*}{$\begin{array}{l}\text { Sample of } \\
\text { Epiphysial } \\
\text { Cartilage }\end{array}$} & \multicolumn{2}{|c|}{$\%$ Nitrogen } & \multicolumn{2}{|c|}{$\%$ Hydroxyproline } & \multicolumn{2}{|c|}{$\begin{array}{l}\text { Mg. Hydroxyproline } \\
\text { per mg. Nitrogen }\end{array}$} \\
\hline & Original & $\begin{array}{l}\text { Defatted and } \\
\text { Dehydrated }\end{array}$ & Original & $\begin{array}{l}\text { Defatted and } \\
\text { Dehydrated }\end{array}$ & Original & $\begin{array}{c}\text { Defatted and } \\
\text { Dehydrated }\end{array}$ \\
\hline Lower end femur (Case) & $2 \cdot 42$ & $13 \cdot 4$ & $0 \cdot 85$ & $5 \cdot 9$ & $0 \cdot 351$ & $0 \cdot 440$ \\
\hline Lower end femur (control) . & $1 \cdot 07$ & $14 \cdot 5$ & 0.434 & $5 \cdot 72$ & $0 \cdot 406$ & $0 \cdot 394$ \\
\hline Upper end femur (Case) & $2 \cdot 53$ & $13 \cdot 2$ & 0.99 & $7 \cdot 6$ & $0 \cdot 391$ & 0.576 \\
\hline Upper end femur (control) . & $1 \cdot 50$ & $13 \cdot 3$ & $0 \cdot 21$ & $3 \cdot 19$ & $0 \cdot 140$ & $0 \cdot 240$ \\
\hline
\end{tabular}




\section{Materials and Methods}

A femur, tibia, humerus and several ribs were fixed in $4 \%$ formaldehyde saline. Control material was obtained at autopsy from newborn babies showing no evidence of any bony abnormality. All bones were decalcified in $25 \%$ formic acid, double embedded in celloidin and paraffin wax, and sections were prepared of their entire length wherever practicable.

Staining Methods. Sections from the case and control material were stained at one and the same time with a variety of stains including Ehrlich's haematoxylin and eosin; iron haematoxylin and van Gieson's stain; cresyl fast violet; alcian blue (Steedman, 1950); dialysed iron (Hale, 1946); the Laidlaw's method for reticulin; the periodic acid Schiff reaction (P.A.S.) (McManus, 1946); and the bi-col method of Wolman (1956).

Substances staining with alcian blue, dialysed iron, and blue with the bi-col stain are accepted as acid mucopolysaccharides.

Sections were also examined with a polarizing microscope to confirm the presence of lamellar bone by its birefringent properties.

Chemical Examination. Samples of epiphysial cartilage from the case and from controls were chemically analysed for hydroxyproline so that a quantitative estimation of collagen content could be made. A Kjeldahl nitrogen assay was also done and the investigation was carried out by Dr. D. L. Woodhouse using the method of Neuman and Logan (1950). The results of the analysis are recorded in the Table. The percentage nitrogen and hydroxyproline is given in respect of the original and dehydrated and defatted material. Hydroxyproline is also given in terms of $\mathrm{mg}$. hydroxyproline per mg. nitrogen.

\section{Results}

Examination of the last column of the Table shows a higher concentration of hydroxyproline in the case material. The percentage of nitrogen in the case material is also higher than in the control based on the original sample weights, but the percentage nitrogen in all specimens after dehydration and defatting is approximately the same.

This indicates that there is an absolute increase in the hydroxyproline content of the case material in both instances and that the relatively greater increase indicated in the third column of the results is due to a greater water and fat content in the control.

\section{Histology and Histochemistry}

Epiphysis. The most outstanding feature in the cartilaginous epiphysis is the great increase in the number of cartilage cells with a considerable reduction in the ratio of intercellular matrix to cell. The cartilage cells are very much smaller in size than normal and the zones of resting, proliferating and maturing cells can easily be seen. The zone of proliferating cells is the same depth in the long axis of the bone as normal but the maturing zone is about two-thirds as deep. The individual cells of the maturing zone do increase in size and become vacuolated towards the epiphysial line as the normal, but they never attain the dimensions of the normal (Figs. 4 and 5).

Consequent upon the tight packing of the smaller cartilage cells there is an increase in the number of ossification rows in the width of the epiphysis. Associated with this, the projecting spicules of cartilaginous matrix on which bone is laid are much narrower and more numerous and there also appears to be an increase in the number of osteoclasts in this area.

Another interesting feature is the pronounced deep pink staining of the cartilaginous matrix of the epiphysis with the van Gieson's stain, although, except near the epiphysial line, a fibrous structure cannot be seen with an ordinary light microscope Under the polarizing microscope, however, birefringent material is prominent in this region. Also in contrast to the normal, this cartilaginous matrix is P.A.S. positive (Figs. 6 and 7), although with the alcian blue, dialysed iron, and bi-col preparations there is no apparent increase in the acid mucopolysaccharide content. This taken into consideration with the results of the chemical analysis indicates an increased collagen content.

Diaphysis. Numerous plump osteoblasts are present around the spicules of cartilaginous matrix made available at the epiphysial line. Bone is laid down in the normal manner though possibly at a greater rate, for at corresponding points from the epiphysial line in this Case and in the control a much thicker layer of bone is present on the spicules of cartilaginous matrix in the Case. An important difference from normal is that the spicules of cartilage are smaller and are replaced by bone at a point nearer the epiphysial line, though they still retain their P.A.S. positive character. In spite of the increased number of ossification rows of the epiphysis and the consequently increased number of cartilaginous spicules available on which bone may be laid there is not an increased number of bony trabeculae in the diaphysis. In fact the bony trabeculae are reduced in number, and several, although they are thicker than normal, are not aligned in the axis of the bony shaft (Figs. 8 and 9).

The bone which constitutes the trabeculae appears to be of normal lamellar type and is birefringent and shows a normal acid mucopolysaccharide content. P.A.S. positive woven bone formed next to the periosteum appears to be pro- 


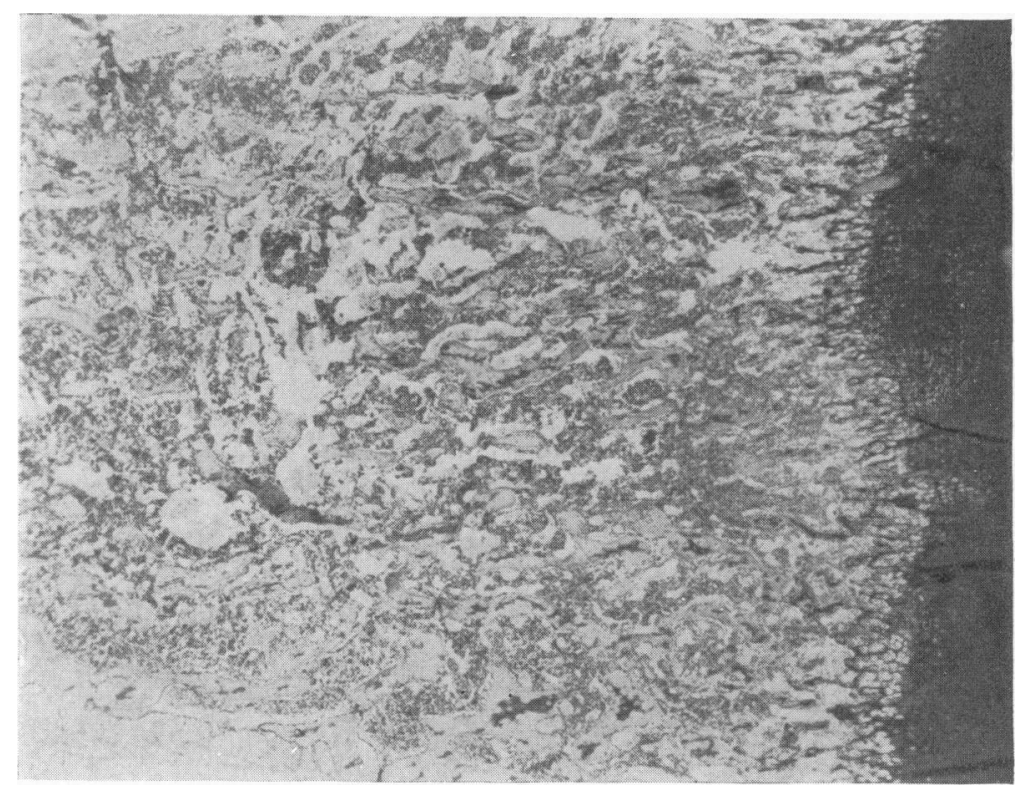

Fig. 8.-Costochondral junction; the spicules of cartilage are replaced by bone nearer to the costal cartilage than normal (the cartilage appears black). (Cresyl fast violet $\times 24$.) 
duced normally and is replaced by lamellar bone further from the epiphysis as in the normal.

\section{Discussion}

Recently, much attention has been focused on micromelia and other skeletal abnormalities associated with the administration of the thalidomide drugs (Morgan, 1962; Leck and Millar, 1962; Lenz, 1962; Pfeiffer and Kosenow, 1962; Somers, 1962; Speirs, 1962; Taussig, 1962). Many photographs of the infants are included in the published reports, but there is no account of the histology or histochemistry.

The administration of several of the alkylating agents has also been shown to produce similar abnormalities in rats (Murphy, 1959). Exposure to $\mathrm{X}$ rays has been shown to cause micromelia (Murphy, 1959; Murphy and Goldstein, 1930), and riboflavine deficiency has been cited as a cause (Warkany, 1947; Nelson, Baird, Wright and Evans, 1956; Kalter, 1959). An association between hypoglycaemia and insulin micromelia in chicks has also been reported by several authors (Landauer, 1947; Zwilling, 1948; Anderson, Crane and Harper, 1959). However, none of these causes can be incriminated in the present case, and the fact that there is a second dwarfed child in an otherwise normal family suggests that an inherited recessive factor is probably responsible.
It is not known whether the histology and histochemistry of micromelia is identical whatever the cause, but it will be seen that the chief abnormalities in this case are (1) the increase in the collagen content of the epiphysial cartilage, (2) the increased rate of ossification and (3) the more numerous smaller cartilage cells. In other respects ossification appears to proceed normally. The cartilage cells mature and align themselves normally so this condition is easily distinguished from achondroplasia where one of the outstanding abnormalities is the failure of the cartilage cells of the epiphysis to align in normal palisades (Knaggs, 1927; Harris and Russell, 1933; Pearce and Brown, 1945; Weinmann and Sicher, 1947; Potter, 1952).

The acid mucopolysaccharide content of the epiphysial cartilage is not apparently disturbed. There is evidence that an increase in acid mucopolysaccharide may inhibit the crystal nucleation process of ossification (Neuman, 1960; Spencer, 1962).

Osteoblasts are present and normal lamellar bone is laid down.

The increased collagen content of the epiphysial cartilage may be important in explaining the abnormally short bones, for it is established that collagen can produce an epitactic growth of hydroxy-apatite crystals (Neuman and Neuman, 1958). Therefore with an increased amount of collagen in the epiphysial cartilage it may be postulated that many more

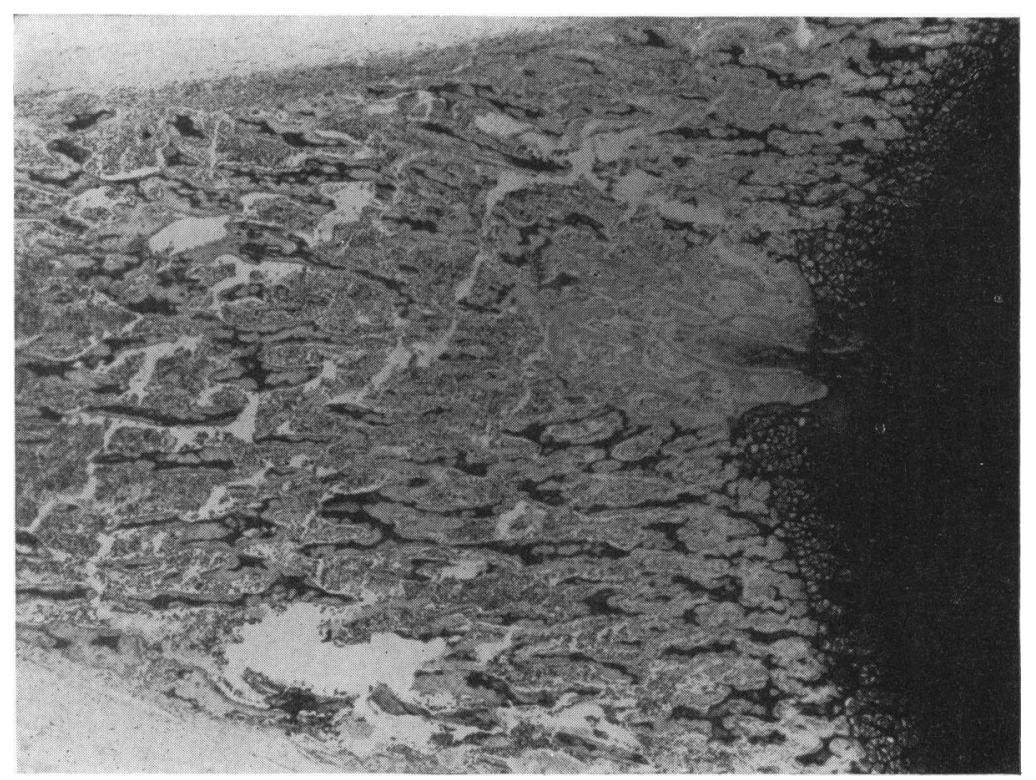

FIG. 9.-Costochondral junction of control. Compare with Fig. 8. (Cresyl fast violet $\times 24$.) 
crystal-seeding points than normal may be available. Hence the laying down of bone mineral may be established at a greater rate than normal with the result that the area of growth at the line of ossification would become prematurely fixed, resulting in an inhibition in the growth in length of the bone.

\section{Summary}

A case of micromelia in a full-term newborn infant is described. Histochemical examination and chemical analysis confirm an increase in the collagen content of the epiphysial cartilage. It is suggested that this may account for the apparent increase in the rate of ossification in the long bones leading to inhibition of growth in their length.

I am grateful to Professor J. W. Orr for helpful criticism and advice, and to Professor H. C. McLaren for permission to use the clinical records. I am also indebted to Dr. D. L. Woodhouse and Mr. G. Fare for the chemical estimations and for help with the interpretation of the results.

\section{REFERENCES}

Anderson, C. E., Crane, J. T. and Harper H. A. (1959), Alterations in growth-cartilage in experimental dwarfism. I. Studies on in growth-cartilage in experimental dwarfism. 1.

Hale, C. W. (1946). Histochemical demonstration of acid polysaccharides in animal tissues. Nature (Lond.), 157, 802.

Harris, H. A. and Russell, A. E. (1933). The atypical growth in cartilage as the fundamental factor in dwarfism and achondroplasia. Proc. roy. Soc. Med., 26, 779.

Kalter, H. (1959). Congenital malformations induced by riboflavin deficiency in strains of inbred mice. Pediatrics, 23, 222.

Knaggs, R. L. (1927). Achondroplasia (chondrodystrophia foetalis). Brit. J. Surg., 15, 10.
Landauer, W. (1947). Potentiating effects of adrenal cortical extract on insulin-induced abnormalities of chick development. Endocrinology 41, 489.

Leck, I. M. and Millar, E. L. M. (1962). Incidence of malformations since the introduction of thalidomide. Brit. med. J., $2,16$.

Lenz, W. (1962). Thalidomide and congenital abnormalities. Lancet, 1, 45.

McManus, J.' F. A. (1946). Histological demonstration of Mucin after periodic acid. Nature (Lond.), 158, 202.

Morgan, B. C. (1962). Thalidomide ("Distaval") and foetal abnormalities. Brit. med. J., 1. 792.

Murphy, D. P. and Goldstein, L. (1930). Micromelia in a child irradiated in utero. Surg, Gynec. Obstet. $50,79$.

Murphy, M. L. (1959). A comparison of the teratogenic effects of five polyfunctional alkylating agents on the rat fetus. Pediatrics, 23, 231.

Nelson, M. M., Baird, C. D. C., Wright, H. V. and Evans, H. M. (1956). Multiple congenital abnormalities in the rat resulting from riboflavin deficiency induced by the antimetabolite galactoflavin. J. Nutr., 58, 125.

Neuman, R. E. and Logan, M. A. (1950). The determination of hydroxyproline. J. biol. Chem., 184, 299.

Neuman, W. F. (1960). In Bone as a Tissue, ed. K. Rodahl, J. T. Nicholson and E. M. Brown, Jr., p. 103. McGraw-Hill, New York.

and Neuman, M. W. (1958). The Chemical Dynamics of Bone Mineral, p. 176. University Chicago Press, Chicago.

Pearce, L. and Brown, W. H. (1945). Hereditary achondroplasia in the rabbit. II. Pathologic aspects. J. exp. Med., 82, 261.

Pfeiffer, R. A. and Kosenow, W. (1962). Thalidomide and congenital abnormalities. Lancet, 1, 45.

Potter, E. L. (1952). Pathology of the Fetus and the Newborn, p. 485. Year Book Publishers, Chicago.

Somers, G. F. (1962). Thalidomide and congenital abnormalities. Lancet, 1, 912.

Speirs, A. L. (1962). Thalidomide and congenital abnormalities. ibid., $1,303$.

Spencer, A. T. (1962). A histochemical study of long bones in osteogenesis imperfecta congenita. J. Path. Bact., 83, 423.

Steedman, H. F. (1950). Alcian blue 8GS: A new stain for mucin. Quart. J. micr. Sci., 91, 477.

Taussig, H. B. (1962). A study of the German outbreak of phocomelia. The thalidomide syndrome. J. Amer. med. Ass., $180,1106$.

Warkany, J. (1947). Etiology of congenital malformations. Advanc. Pediat., $2,1$.

Weinmann, J. P. and Sicher, H. (1947). Bone and Bones. Fundamentals of Bone Biology, p. 147. Kimpton, London.

Wolman, M. (1956). A histochemical method for the differential staining of acidic tissue components (particularly groundsubstance polysaccharides). Bull. Res. Coun. Israel E, $6 \mathrm{E}, 27$.

Zwilling, E. (1948). Association of hypoglycemia with insulin micromelia in chick embryos. J. exp. Zool., 109, 197. 